\title{
Con sangre en las manos. La construcción de la novela negra española y mexicana a partir de dos antihéroes sangrientos: Pepe Carvalho y Filiberto García
}

\author{
JAFET ISRAEL LARA
}

El estudio de la serie protagonizada por Pepe Carvalho es trascendental para comprender el desarrollo de una novela negra que sacó del letargo a las literaturas policíacas españolas:

Part of the normalization process was what many have referred to as a "boom" in Spanish detective fiction from the mid-seventies to the mid-eighties. While Spanish readers as a whole were turning toward homegrown writers, Spanish mystery readers, who had long been accustomed to works imported from France, Britain and the U.S., had very few mystery writers of quality to turn to in the Spanish context. Then along came Pepe Calvalho, whose appearance in Tatuaje initiated the so-called boob in Spanish mystery writing (O’Donnell 138). ${ }^{1}$

El propósito de esta investigación no es centrarse en el estudio de $\mathrm{Ta}$ tuaje (1974) la primera novela de la serie policíaca protagonizada por Pepe Carvalho, sino en ahondar en Yo maté a Kennedy (1972), la protohistoria carvalhesca que en más de una ocasión es olvidada y sin la cual es imposible comprender a Pepe Carvalho, ya que el ayer es un elemento intrínseco al detective privado y a su comportamiento aparentemente contradictorio. Pero aún más.

Este estudio se enfoca hacia la comparación entre Carvalho y su colega mexicano Filiberto García, protagonista de El complot mongol (1969) y personaje clave para la evolución del neopolicial mexicano que surgió en los setenta e inició la lenta reconfiguración de una novela policíaca mexicana clásica. Una novela que influyó notablemente en la obra de $-$

${ }^{1}$ Parte del proceso de normalización fue lo que se ha denominado como el "boom" en la novela policíaca española que se dio de mediados de la década de los setenta a mediados de los ochenta. Mientras los lectores españoles fijaron la mirada en los autores de su país, aquellos que leían textos de misterio estaban a acostumbrados a novelas importadas de Francia, Gran Bretaña y Estados Unidos, ya que habían muy pocos escritores españoles de misterio de calidad. Entonces llegó Pepe Calvalho, cuya aparición en Tatuaje inició el llamado boom de la literatura de misterio en la literatura española. La traducción es nuestra. 
Paco Ignacio Taibo II, Rafael Ramírez Heredia, Mariano Flores Castro y Elmer Mendoza, entre otros.

Al realizar un estudio comparativo de los programas narrativos dentro del recorrido narrativo de ambos personajes se dejará constancia de un hecho innegable. La novela negra española y la mexicana encuentran sus raíces en dos investigadores contradictorios, con un pasado convulso y con las manos manchadas de sangre, pero también críticos hacia las revoluciones que defendieron y los defraudaron.

El primer paso para observar esta oscura paradoja es el rastreo biográfico de ambos personajes, el cual se torna complicado en el caso de Pepe Carvalho debido a la propia complejidad narrativa planteada por Vázquez Montalbán en Yo maté a Kennedy, pero también a la necesidad de recurrir a un ejercicio intertextual con otras novelas de la serie protagonizada por el detective gallego.

La construcción de la identidad en el pasado. Revolucionarios, espías y asesinos

Una de las grandes dudas que suscita Pepe Carvalho es su identidad, ¿quién es realmente? La primera alusión sobre él se ofrece en una charla entre Jaqueline Kennedy y el guardaespaldas protagonista de Yo maté a Kennedy. En ella se deja constancia de una peligrosidad que se magnifica al relacionarlo con la misteriosa Bacterioon: "¿Cómo entra en contacto Pepe Carvalho con Bacterioon? [...]" (Vázquez Montalbán 34).

Para Edgar Hoover, Carvalho es un gallego que no representa mayor peligro, ya que es "un buen profesional del crimen, pero no por ello deja de ser lo más parecido a un puertorriqueño" (27). El todopoderoso director del FBI deja entrever que ni el gallego ni Bacterioon existen: son rumores de complots internacionales. Sin embargo, Carvalho es muy real. Es precisamente esa inmaterialización corpórea y su puesta en escena fantasmal la principal arma de Carvalho:

\footnotetext{
Ninguna descripción de Pepe Carvalho coincide con la anterior y ya no queda ninguna esperanza de que pueda coincidir con la ulterior. En La Paz, tras el atentado contra Paz Estensoro, Carvalho era un hombre alto, aquilino, muy moreno, de ojos magnéticos. En Siria, después de la última intentona del Baas, Carvalho es un oscuro, pequeño hombre calvo con lentes bifocales. En Kenya sería un tragasables rubio panocha. Todos los informes sobre él son muy secretos, pero también muy inútiles [...] Con él llega la muerte, silba y se lleva las vidas inmantadas (34-35).
} 
La segunda identidad de Carvalho permanece oculta bajo el anonimato del narrador autodiegético de Yo maté a Kennedy, uno de los agentes del servicio secreto norteamericano encargado de la seguridad del presidente Kennedy y de su familia.

Un guardaespaldas que es también un agente de la CIA, tal y como él mismo confiesa: "[...] Morrison, mi inmediato superior, es de la misma opinión. Pero Hoover, que no nos puede tragar a los de la CIA se empeña en la búsqueda del cuerpo" (34).

Es más allá de Yo maté a Kennedy, en las historias que Pepe Carvalho protagonizará a partir de Tatuaje, cuando el ex-espía, convertido en detective privado en Barcelona, revela su convulso pasado.

En Asesinato en el Comité Central (1981) se conoce que fue un preso político por sus ideas comunistas, sin olvidar su pasado en la CIA: “[...] Casi me había olvidado de que en cierta ocasión fui comunista. Como había olvidado también que trabajé en la CIA durante cuatro años. ¿Conocían este dato?" (Vázquez Montalbán 29).

Un pasado ambiguo y paradójico, tal y como se señala en el Balneario (1986): "Es usted un tipo curioso, Carvalho, refleja en sí mismo el dramatismo de nuestro tiempo, ese bandazo del Partido Comunista a la CIA" (Vázquez Montalbán 170).

El detective intenta justificar en La soledad del manager (1977) su paradoja ideológica, aunque nunca ofrece una respuesta clara a ese interrogante: "Empecé dando clases de castellano [en Estados Unidos] sin saber qué era la CIA y luego me divirtió el juego" (Vázquez Montalbán 53).

Una labor en la CIA que en El premio (1996) se orienta hacia actividades desestabilizadoras de gobiernos de izquierda, como es el caso de su viaje a la República Dominicana, aunque es en Los pájaros de Bangkok (1983) en donde el detective privado resume su sangriento pasado: "Estas manos son manos asesinas. He sido agente de la CIA y he matado todo lo que podido" (Vázquez Montalbán 115).

En contraparte al ex comunista reconvertido en agente de la CIA que trabaja en la vigilancia de la seguridad del presidente de Estados Unidos, se encuentra Filiberto García, un personaje cuyos antecedentes se reducen al mundo ficcional de El complot mongol (1969) de Rafael Bernal.

García es un veterano de la Revolución mexicana, tal y como el mismo confiesa: "En la Revolución era otra cosa, pero entonces yo era un 
muchacho. Asistente de mi General Marchena, uno de tantos generales" (Bernal 9).

El mexicano es un hombre de armas que formó parte de la policía, pero al tener una gran experiencia matando gente fue reclutado por la Dirección de Investigaciones Políticas y Sociales, la policía secreta, el brazo policial más temible del aparato de seguridad mexicano. Una actividad que se traduce en una muestra de su lealtad al gobierno:

- Yo creo, García, que usted es un hombre leal a su gobierno y a México. Estuvo en la revolución con el general Marchena y luego, después de aquel incidente con la mujer, ingresó en la policía del estado de San Luis Potosí. Cuando el general Cedillo se levantó en armas, usted estuvo en su contra. Ayudó al Gobierno federal en el asunto de Tabasco y en algunas otras cosas. Ha trabajado bien en la limpieza de la frontera y su labor fue buena cuando los cubanos pusieron ese cuartel secreto (Bernal 6).

No obstante, García no es un agente secreto como Carvalho. Es una herramienta de represión que ejecuta a los opositores políticos, tal y como él mismo lo confiesa: "[...] Yo solo soy pistolero profesional, matón a sueldo de la policía [...]" (34).

A diferencia de Pepe Carvalho, Filiberto García no tiene una ideología política definida. Él simplemente realiza sus actividades bajo el cobijo de la jerarquía militar en la que solo se cumplen órdenes, sin poner ninguna clase de excusa, tal y como se observa en la reunión secreta que tiene con el ministro del interior de México:

-Sin embargo hay una cosa que no queda clara en su expediente. No se habla de sus simpatías o sus intereses políticos. ¿Simpatiza con el comunismo internacional? - No.

$-¿$ Tiene fuertes sentimientos antinorteamericanos?

-Yo cumplo órdenes.

-Pero debe tener alguna filias y algunas fobias.

-Digo, algunas simpatías o antipatías en el orden político.

-Cumplo las órdenes que se me dan (7).

De este modo, el conflicto armado en México y la posterior represión estatal determinan la identidad de un policía-sicario que solo responde a una estructurada jerarquía que le permite evadirse de cualquier juicio moral.

Aunque Carvalho y García son instrumentos de represión estatal orientados a actividades encubiertas y asesinatos, existen serias diferencia en el espacio de sus actividades. Carvalho actúa generalmente en el 
extranjero, mientras que García lo hace en México. Estas diferencias se acentúan en su propia formación como agentes represores.

Carvalho es un espía y asesino profesional que aprendió a matar gracias a las clases impartidas en la escuela de la CIA dirigida por el veterano agente Phileas Wonderful:

Aprender a matar fue lo más difícil. Las vacilaciones decía el profesor, generalmente, no preceden de una repugnancia natural, sino cultural [...] Primero matábamos peleles, perfectas reproducciones humanas. Les dábamos nombres humanos. Convivíamos con ellos. Nos inyectaban drogas del afecto, les teníamos aprecio. De pronto nos llegaba la orden de matanza en una clave codificada: cada signo traducía un ademán (Vázquez Montalbán 14, 16)

García aprendió a matar para sobrevivir. Primero durante la Revolución mexicana y después durante la postguerra revolucionaria. Es un pistolero que se ha vuelto profesional con el paso del tiempo en un proceso de enseñanza distinto al del estudiante a espía y asesino Pepe Carvalho:

Y el gringo usa revólver treinta y ocho especial de la policía. Tal vez porque son expertos. Saben judo, karate y estrangular con cordones de seda [...] A nosotros en México no nos enseñan todos esos primores. A nosotros sólo nos enseñan a matar. Y tal vez ni eso. Nos contratan porque ya sabemos matar. No somos expertos, sino aficionados (Bernal 68)

Aunque su formación como asesinos es distinta, es evidente que el pasado de ambos personajes resulta ser similar dado que ambos responden a prerrogativas represoras estatales. Este es solo el primer paso ante el descubrimiento de que Carvalho y García, en los que se sustenta el origen de la novela negra española y la mexicana, tienen las manos manchadas de sangre.

La violencia de estos dos personajes responde a factores de supervivencia frente al desencanto de sus revoluciones que, de cierto modo, han contribuido a sus frustraciones personales y que tendrán influencia en sus programas narrativos que los llevarán a un final no del todo planificado.

\section{El desencanto revolucionario del pasado}

La visión que ofrece Vázquez Montalbán en Yo maté a Kennedy es la de la crítica mordaz hacia la burguesía norteamericana de esos primeros 
años de la segunda mitad del siglo XX. Un mundo de ensueño en donde la familia presidencial descansaba plácidamente:

Sobre el césped, la familia Kennedy comía emparedados. Atardecía. Las aguas de la piscina recuperaban una falseada tranquilidad bajos las sombras grises. Un criado negro pescaba hojas muertas y flotantes. Robert Kennedy hacía la vertical y sus dos hijos mayores le imitaban [...] John Fitzgerald Kennedy fumaba una larguísima pipa de la paz subido a la copa de un castaño de Indias (Vázquez Montalbán 4).

En esas descripciones idílicas, Vázquez Montalbán encuentra la mejor oportunidad para delinear su visión de una sociedad norteamericana que descansa, mientras en Vietnam, bajo las órdenes directas del presidente/rey, llegan fuerzas especiales norteamericanas junto con un contingente de más de 16 mil hombres. Un Kennedy que incrementó los gastos de defensa un $20 \%$ y que duplicó el número de cabezas nucleares y de submarinos estratégicos (Múgica 68).

Una visión que también posee Rafael Bernal en su crítica hacia la nueva burguesía que ha tomado las riendas de México queriendo construir otro país: edificios comerciales, complejos urbanos, plazas de toros, áreas industriales, complejos turísticos, hoteles, mansiones y lujosas villas van apareciendo rápidamente por el país (Novo 731).

Una burguesía mexicana con excesivos gustos europeizados: “¿Usted es existencialista? ¿Le gusta el arte figurativo? Le deben gustar los calendarios de la Casa Galas. ¿Y qué de malo tiene los calendarios de la Casa Galas" (Bernal 11-12).

Yo maté a Kennedy y El complot mongol ofrecen una visión crítica de la burgesía así como una autocrítica del marxismo y la Revolución mexicana, del dogmatismo de los correligionarios comunistas y del abuso por parte de los herederos de la Revolución.

Por un lado, se aprecia al comunista que ironiza y crítica despiadadamente las interferencias del fanatizado marxismo-leninismo en el ámbito más íntimo del ser humano: la familia (Moya Bedoya 29). Muriel, la esposa de Pepe Carvalho, es la perfecta marxista que encuentra conspiraciones por todos lados, pero sobre todo en su marido, un pequeño burgués infectado por la mecánica laboral capitalista:

Yo estaba esclavizado por mis relaciones de producción de intelectual, productor individual, con remuneración a destajo, lo que me impedía una mínima comprensión de la realidad a partir de una conciencia de clase [...] Durante todo aquel tiempo no había manifestado sus profundas insatisfacciones porque esperaba que una adecuada re- 
educación, un programa de sanas lecturas y compañías podían ayudarme a superar o, al menos a ser consciente, de la alienación padecida por la mecánica de mi trabajo (Vázquez Montalbán 86)

A esa irrupción del marxismo como elemento que desgaja a la esencia misma de la sociedad, la familia, provocando el amargo divorcio del protagonista, se le une el aspecto más dogmático e intolerante del comunismo: la imposición de valores sociales y de la educación de los hijos.

Si Carvalho no supera su enajenación burguesa a través de todo un programa educativo de lecturas marxistas, su hija será confiada a un miembro diligente y consciente del partido comunista que la educará bajo los preceptos del partido. Pero no solo eso. Según Muriel, Pepe debe abandonar cualquier apelación a la patria potestad:

Por todo ello me rogaba que atendiera a razones, que no creara sucios problemas legales, pues de todos es sabido y reconocido que el Derecho es una superestructura en conexión con los intereses de la clase dominante y que, en definitiva, todas las prerrogativas de la patria potestad eran consecuencia de la solapada conspiración para que la jerarquización familiar respondiera a la jerarquización parafeudal de un sistema parafascista (87).

La irrupción de la política en el orden doméstico y la politización de este último son motivo de una ácida crítica de Vázquez Montalbán que pulveriza los dogmas comunistas reflejados en Muriel, los cuales demuestran la incapacidad del comunismo a negociar inteligentemente con realidades fácticas (Moya Bedoya 29).

En el otro lado, se aprecia la visión crítica de una Revolución robada. Filiberto García ha sido testigo de todos los avances realizados por los postrevolucionarios que han marcado sus diferencias respecto a los "padres de la Revolución" como Madero o Zapata, a todos los que hicieron la rebelión a balazos y que son considerados como un estorbo para el futuro del país:

Y mientras, México progresa. Ya va muy adelante. Usted es de la pelea pasada. A balazos no se arregla nada. La Revolución se hizo a balazos. ¡Pinche Revolución! Nosotros somos el futuro de México y ustedes no son más que una rémora. Que lo guarden allí, donde no se vea, hasta que lo volvamos a necesitar [...] Porque nosotros somos los que estamos construyendo a México desde los bares y coctel lounges, no en las cantinas como ustedes los viejos (Bernal 4) 
Una vez acabada la revuelta armada, los herederos de la Revolución impusieron el fin de la lucha de clases, y el principio de unas relaciones basadas en la cooperación y la conciliación. No obstante, la postrevolución terminó traicionando al pueblo a través de un nuevo sistema político, semejante a la dictadura de Porfirio Díaz, que olvidó sus compromisos sociales.

Esta forma de gobernar lleva al protagonista a velar por sus propios intereses: "¿y qué ha hecho el gobierno por mí? ¡Pinche sueldo que paga! Si no fuera porque uno de aguza, con o sin gobierno, se lo lleva el tren, con todo y la lealtad" (36).

El pasado de Carvalho y García se conjugan con un enorme desencanto hacia sus propios ideales. Ninguno es un traidor, sino que son supervivientes de procesos históricos. Dos configuraciones que están presentes, en lo profundo, en sus respectivos programas narrativos.

\section{Programas narrativos en el recorrido narrativo de Pepe Carvalho y} Filiberto García

Un programa narrativo es una sucesión de estados y transformaciones que se encadenan sintagmáticamente en base a una relación sujeto/objeto y de su correspondiente transformación que conlleva al cambio de estado de un sujeto (Greimas 320).

El programa narrativo no es un sucesión encadenadora homogénea, sino que puede evolucionar semióticamente hacia otros programas narrativos dependiendo de las circunstancias de la propia diégesis.

En el caso de Pepe Carvalho existen tres distintas ramificaciones programáticas. Esto se debe a la complejidad del propio Carvalho, el cual presenta tres distintas identidades que se observan a continuación:

\begin{tabular}{|c|l|}
\hline $\begin{array}{c}\text { Pepe Carvalho } \\
\text { identidad actancial }\end{array}$ & \multicolumn{1}{|c|}{ Programa Narrativo } \\
\hline Guardaespaldas / Agente del servicio & $\begin{array}{l}\text { Proteger al presidente John F. Kennedy de } \\
\text { cualquier peligro que amenace su vida } \\
\text { Intentar matar al presidente Kennedy } \\
\text { siguiendo las órdenes de la CIA }\end{array}$ \\
Agente de la CIA & $\begin{array}{l}\text { Intentar matar al presidente Kennedy } \\
\text { siguiendo las órdenes de Bacterioon }\end{array}$ \\
\hline Agente de Bacterioon & \\
\hline
\end{tabular}


Respecto a Filiberto Garcia su identidad es la misma, pero sus programas narrativos evolucionarán a lo largo de la diégesis principal, tal y como se aprecia seguidamente:

\begin{tabular}{|c|l|}
\hline \multicolumn{1}{|c|}{ Filiberto García } & \\
\hline \multirow{3}{*}{ Agente de la policía secreta mexicana } & Descubrir si el complot mongol es cierto \\
& o falso \\
& Evitar el atentado en contra del presiden- \\
& te de los Estados Unidos \\
& Evitar el atentado en contra del presiden- \\
& te de México \\
& Descubrir quién asesinó a su amante \\
& Marta Fong \\
\hline
\end{tabular}

Dentro de la configuración semionarrativa de Yo maté a Kennedy y El complot mongol es posible identificar los estados y las transformaciones de Pepe Carvalho y Filiberto García a partir de la narración de sus acciones. Dentro de dicha configuración se encuentran dos enunciados que jugarán un papel esencial en el recorrido narrativo de ambos personajes: el de estado y el de hacer.

Generalmente, dentro de la dualidad de estado y de hacer el agente actancial se encuentra en un estado de inactividad que tiene que modificarse, ya que de lo contrario no hay un encadenamiento semionarrativo dentro de la diégesis.

La manera por la cual se va a dar ese cambio de estado es a partir de un recorrido narrativo compuesto por cinco elementos: la "transformación", la "performancia", la "competencia", la "manipulación" y la "sanción". De igual modo será necesario describir correctamente la naturaleza del actante:

El papel, o los papeles, que juega en relación a su posición en el recorrido narrativo, su integración en el nivel posterior (en los actores de manera especial) así como las modalizaciones que sufre: el actante, a medida que va efectuando su recorrido narrativo, puede ir uniéndose a cierto número de estados narrativos o roles actanciales, que a su vez irán definiéndose en función de la posición del actante dentro del recorrido narrativo y del particular vertimiento modal que adopte el propio actante (77).

De acuerdo a esto, el actante/sujeto podrá estar dotado de modalizaciones tan simples como lo son el querer-hacer, saber-hacer o el poderhacer, las cuales van a dar capacidades de intervención o no intervención 
en las acciones y en el cambio de los programas narrativos del agente español y del mexicano.

El primer paso del recorrido semionarrativo es el de la "transformación". En ella se da un cambio de estado del personaje, de uno de noactividad o disjunción a uno de actividad o conjunción. Este cambio de estado demanda la existencia de un hacer transformador que permitirá la puesta en marcha del recorrido semionarrativo actancial.

En Yo maté a Kennedy este hacer transformativo se da del siguiente modo. Primero, Carvalho-guardaespaldas que recibe órdenes del director de la CIA, Allan Dulles, y del FBI, Edgar Hoover, para proteger al presidente Kennedy. Segundo, Carvalho-asesino/agente de la CIA que es reclutado para matar a Kennedy por su jefe Morrison. Tercero, Carvalhoagente de Bacterioon que en un momento indeterminado recibe la orden de matar a Kennedy.

En estos dos últimos haceres transformativos queda constancia del papel de doble agente de Pepe Carvalho, tal y como lo explica Morrison a míster H: "-Cuando le propusimos matar a Kennedy vio la oportunidad de cobrar un doble sueldo con un solo tiro: el que ya había estipulado con Bacterioon y el que le ofrecía usted" (Vázquez Montalbán 104). Una propuesta que el propio Carvalho corrobora: "Nancy, he pescado algo gordo, si me ayudas, ésta es la definitiva [...] Ya estoy decidido, me ha ofrecido mucho dinero" (113).

Respecto a Filiberto García este ha sido llamado a una junta secreta por su superior, un hombre conocido como "El Coronel", en la que asiste Rosendo del Valle, ministro del Interior mexicano, que le pide a García averiguar si es verdadero el rumor sobre un atentado en contra del presidente de los Estados Unidos, que en unos días visitará México.

[...] Y ese va a ser su trabajo. Va a mezclarse con los chinos, va a captar cualquier rumor sobre gente nueva que haya llegado o movimiento entre ellos

- ¿Y si el rumor es cierto y encuentro a los terroristas?

-Obrará, en ese caso como le parezca adecuado (Bernal 8).

Para que se active la "transformación" de los estados de disjunción o inactividad y comience el recorrido narrativo de Carvalho y García, es necesario un elemento catalizador que provoque ese cambio de estado en ambos agentes.

Con la "performancia" puede aparecer un nuevo agente actancial denominado sujeto operador. Este intervendrá directamente en la historia 
debido a que posee la capacidad de motivar la "transformación" de los estados de junción de los agentes protagonistas. Pero ¿quiénes son los sujetos operadores dentro de Yo maté a Kennedy y El complot mongol?

En caso de Pepe Carvalho este requiere los siguientes enunciadores del hacer transformativo. Primero como agente del servicio secreto por el cual responde directamente ante Morrison, su superior inmediato, y el presidente Kennedy. Segundo, como parte del complot contra el presidente, Carvalho responde ante Morrison y míster $\mathrm{H}$, es decir, ante la agencia de inteligencia norteamericana. Tercero, la posición de Carvalho como agente doble al servicio de la CIA y Bacterioon implica un mayor grado de complejidad, la cual se revela al final de Yo maté a Kennedy:

La primera sospecha de que podía tratarse de una doble vida la tuvimos cuando estuvo a punto de ser asesinado Frondizi durante su gira europea. Pepe Carvalho era el encargado de matarle y nuestro hombre era el jefe de la guardia de seguridad del presidente [...] Pepe Carvalho trabajaba para Bacterioon y al nosotros contratarle también sabía que seguía trabajando para Bacterioon (Vázquez Montalbán 101, 104).

Por lo que se refiere a Filiberto García este responde ante dos enunciadores de su hacer transformativo: "El Coronel", su jefe inmediato, y Rosendo del Valle, responsable de la política de seguridad interior de México: "Pero tenemos que actuar, tenemos que saber la verdad. Y la verdad que llegue usted a averiguar, señor García, sólo podemos conocerlas el Coronel y yo. Nadie más, ¿entiende?” (Bernal 7).

Para que los protagonistas puedan realizar la "transformación" proyectada, es decir, para que la "performancia" del sujeto operador sea posible, este último tiene que estar capacitado para el hacer transformacional correspondiente (Prada Oropeza 69). En otras palabras, se debe tener una "competencia".

La modificación de la relación del sujeto operador, en este caso los agentes ficcionales responsables de la "transformación" del estado de junción de los programas narrativos de Carvalho y García, con el hacer se le llamará modalización del hacer y constituirá cuatro dimensiones que otorgan la capacidad de transformar cualquier programa narrativo:

\begin{tabular}{|c|l|}
\hline $\begin{array}{c}\text { Virtualidad } \\
\text { Deber-Hacer/Querer-Hacer }\end{array}$ & $\begin{array}{l}\text { Estas dos modalidades de la virtualidad } \\
\text { manifiestan el papel del Sujeto operador } \\
\text { con respecto a su hacer }\end{array}$ \\
\hline Actualidad & $\begin{array}{l}\text { Determinan el modo de acción del Sujeto } \\
\text { operador, su capacidad de hacer }\end{array}$ \\
\hline Poder-Hacer/Saber-Hacer
\end{tabular}




\begin{tabular}{|c|l|}
\hline $\begin{array}{c}\text { Realizantes } \\
\text { Hacer-Ser }\end{array}$ & $\begin{array}{l}\text { Afecta los enunciados de estado y logra } \\
\text { su transformación. Se relaciona con la } \\
\text { realización de la acción en concreto }\end{array}$ \\
\hline $\begin{array}{l}\text { Veridictiva } \\
\text { Parecer-Ser }\end{array}$ & $\begin{array}{l}\text { Califica la relación como verdadero, } \\
\text { falso, engañosa, secreta }\end{array}$ \\
\hline
\end{tabular}

En el primer caso, los sujetos operadores de la programación narrativa de Carvalho son Kennedy, Morrison, míster H y Bacterioon. En el segundo caso, los programas narrativos de García están bajo el control operativo de "El Coronel" y Rosendo del Valle.

Dentro del plano de la virtualidad, estos cinco sujetos operadores tienen la capacidad para llevar a cabo su trabajo. Kennedy es quien da las órdenes directas para su protección, mientras Morrison asigna el trabajo inmediato al Carvalho-guardaespaldas. El mismo Morrison es el responsable de reclutar a Carvalho para el complot en contra de Kennedy que ha sido organizado por míster $\mathrm{H}$. Bacterioon, como entidad, es la que le paga a Carvalho para ser un doble agente y eliminar al presidente de Estados Unidos. Del Valle es el máximo responsable de la política interna de México y "El Coronel"es el que dirige las operaciones de la policía secreta a la que pertenece García.

Los seis sujetos operadores reciben a su vez modalidades de actualidad, las cuales determinarán el modo de acción y la capacidad de hacer. Asimismo actualizan los valores de los sujetos operadores, la primera en relación a la capacidad de llevar a cabo una acción, la segunda en torno a prever y programar actividades necesarias para la realización de los programas narrativos de Pepe Carvalho y Filiberto García.

Kennedy, Morrison, míster H, Bacterioon, del Valle y "El Coronel" están en conocimiento de una información clave que les permite ejercer la modalidad realizante con la que pueden transformar el estado de no actividad o disjunción del agente español y del mexicano.

Para que un sujeto se invista de las modalidades de la "competencia" previamente debe ser avisado del estado en el que se encuentra y la posibilidad de transformarlo. Es decir, debe ser manipulado por otro sujeto que le comunicará sobre el programa narrativo visual. A este sujeto se le denomina sujeto destinador (Prada Oropeza 71). Por medio de la "manipulación" el sujeto manipulador llevará a los protagonistas a una posición de falta de libertad.

En Yo maté a Kennedy la "manipulación" se ejerce a través de distintas perspectivas. En la primera, la de Carvalho-guardaespaldas, es el 
propio Kennedy y Morrison. En la segunda, oculta detrás de las actividades de la agencia de inteligencia norteamericana, son Morrison y míster $\mathrm{H}$ quienes manipulan al Carvalho-agente de la CIA.

Dentro del tercer programa narrativo, el de agente de Bacterioon, el propio Pepe Carvalho rompe la dependencia semiótico-narrativa en una confesión al lector:

Voy a matar a ese viejo. Nadie me lo impedirá y después dejaré todo esto. Entre lo que me paga Bacterioon y lo que me paga mister $\mathrm{H}$ tengo una espléndida madurez y una tranquila vejez aseguradas. Como en las películas bonitas, volveré a mi tierra, intentaré recuperar a Muriel y a la niña, cambiaremos de nombres y emprenderemos una nueva vida sin que nada nos falte (Vázquez Montalbán 112).

Quienes ejercen la «manipulación» sobre los programas narrativos de Filiberto García son Rosendo del Valle y "El Coronel". Estos dos personajes destinan a García la misión de descubrir si el complot, proveniente de la Mongolia exterior, es cierto o no.

De ser cierto García debe de obrar de la manera más adecuada. Así mismo, se observa que al final de la historia "El Coronel" será el único sujeto destinador de García, ya que le ordenará descubrir a los asesinos y detener el atentado en contra del presidente de México. Lo interesante en este programa narrativo es que se da una absoluta independencia del propio Filiberto García: asesina a del Valle y al general Miraflores desobedeciendo las órdenes del "El Coronel":

Disparó una sola vez. La bala le entró a del Valle entre los ojos, le desbarató la cara y le quitó, junto a los anteojos, el aspecto de hombre importante y venerable. García puso la pistola en la mano del cadáver del General y guardó la suya propia. Luego fue al teléfono $[\ldots]$

-Estoy en la casa del señor del Valle. Parece que tuvieron un disgusto, se hicieron de palabras y se dieron de balazos.

-¿Están muertos?

-Sí.

-Espéreme allá.

-Lo siento, mi Coronel, pero tengo que hacer algunas cosas. Colgó el teléfono [...]

(Bernal 92-93).

No obstante, falta algo primordial en este recorrido: ¿Cómo saber que la actuación del investigador fue correcta? ¿Quién lo decide? Para eso es necesario un juicio de valor, o "sanción", de un sujeto capacitado para aprobar el trabajo del investigador. 
La parte final del recorrido narrativo es la "sanción", el momento en el cual se definirá el resultado de la "transformación" de los programas narrativos de los sujetos de estado, es decir, el juicio sobre las acciones de los protagonistas que lo llevara a cabo un sujeto que, en muchos ocasiones, es el propio sujeto operador (Prada Oropeza 74).

Al analizar los tres programas narrativos de Pepe Carvalho se aprecia que la "sanción" es distinta dependiendo de la perspectiva. Es cierto que como guardaespaldas fracasa debido a que el presidente Kennedy es asesinado, pero dicho juicio de valor no afecta al agente español. La realidad es que Pepe Carvalho es un agente de la CIA reclutado precisamente para infiltrarse dentro del servicio secreto y tener una posición privilegiada en el momento de ejecutar el complot en contra del presidente:

-No hay duda de que ha trabajado usted muy bien, Morrison. Ni siquiera yo era uno de los entusiastas de su plan. Pero las cosas han salido muy bien. Pepe Carvalho ha actuado en el momento oportuno, ha estado donde usted quería que estuviera. Se ha comportado como usted, como yo, queríamos que se comportara... (Vázquez Montalbán 98).

Respecto al tercer programa narrativo, este mantiene la misma "sanción" que en el anterior, aunque en ningún momento aparece el agente operador Bacterioon. Sin embargo, existe una última "sanción", aunque esta no forma de ningún programa narrativo de Carvalho: la de la madre del agente español que, a pesar de todo, no reniega de su propio hijo:

$\mathrm{Y}$ ahora nos enteramos que has matado al presidente de América. Ya no me quedan lágrimas para llorarte [...] ¿Qué te había hecho el presidente de América, Pepe? ¿No te das cuenta que dejas una viuda y dos hijos sin padre? No sabes tú, desgraciado, la falta que hace un padre en una casa. Yo tuve que sacarte adelante, mientras tu padre estaba en la cárcel [...] Te envío una manta y una fiambrera con carne empanada para cuando te detengan. Dime si te dejan meter termos y te haría un buen caldo gallego (111).

En el caso de Filiberto García es preciso apreciar los cuatro distintos programas narrativos que forman parte del recorrido narrativo del agente mexicano. En el primer programa narrativo, García lleva pruebas a sus superiores, que sancionan las actividades del investigador declarando que el complot es verdadero. 
-Después de su brillante investigación, señor García, creo que podemos afirmar que se está utilizando dinero que proviene de la China para... para llevar a cabo un atentado en México.

-Así parece ser, señor del Valle - dijo el Coronel (Bernal 47).

El nuevo programa narrativo de García es detener, con la ayuda de un norteamericano y de un soviético, el atentado. En este programa narrativo el principal sujeto sancionador, del Valle, desaprueba el trabajo de García y modifica, en su papel de sujeto operador, el estado del investigador que vuelve a la inactividad.

No obstante, "El Coronel", el sujeto sancionador secundario, decide que García debe proseguir con su investigación, accionando un tercer programa narrativo en el cual se descubrirá que el atentado es realmente en contra del presidente de México:

-Puede ser - dijo el Coronel como hablando para sí mismo-, que alguien, tal vez los mismo rusos o algunos gringos se enteraron del rumor y pensaron que era una buena oportunidad para liquidar al Presidente y echarle la culpa a los chinos.

-Algo así, mi Coronel

-Siga investigando.

-Sí, mi Coronel [...]

-Y otra cosa, García

García, que se había puesto de pie, se detuvo.

- De esto me informa tan sólo a mí. ¿Entiende? (Bernal 70).

De este modo, solo existirá un solo sujeto sancionador, "El Coronel" debido a que Rosendo del Valle perderá dicha condición al ser uno de los cabecillas del complot para asesinar al presidente de México.

En el cuarto programa narrativo, García está dispuesto a vengar la muerte de su amante, Marta Fong, lo cual lo lleva a matar a Rosendo del Valle al determinar, erróneamente, que este es el asesino de la mujer.

Queda la gran duda de quién sanciona esta última misión. Tal parece que puede ser el lector. No es posible que Laski o "El Coronel" sean los sujetos sancionadores dado que no poseen el conocimiento necesario para llevar a cabo un juicio de valor o "sanción" algo que el lector sí puede realizar gracias a su contacto total con toda la historia. El conocimiento ayuda a sancionar y juzgar.

\section{Conclusiones}

Vázquez Montalbán escribió Yo maté a Kennedy en una época de auge por el experimentalismo como parte de una vanguardia que entró de 
lleno en una España con una moribunda dictadura. Una experimentación en el que la indagación de las posibilidades expresivas y los límites del lenguaje adquieren un papel primordial que se plasma en una suerte de antinovela (Moya Bedoya 26).

Por su parte, Rafael Bernal apostó por un texto transgresor en el que incorpora elementos de la novela experimental mexicana, que con Al filo del agua (1947) de Agustín Yáñez había dado sus primeros pasos y que se desarrollaría con El llano en llamas (1953) y Pedro Páramo (1955) de Juan Rulfo, en el que las expresiones escritas transforman el excesivo academicismo de las letras mexicanas.

Yo maté a Kennedy y El complot mongol apelan a los recursos experimentalistas como el monólogo, la explotación de los contenidos expresivos, la transgresión morfosintáctica y ortográfica, a la combinación de diversos discursos, aunque, a diferencia de Bernal, Vázquez Montalbán hace más evidente su impostura ante los formalismos, ya que ubica su texto en la difusa frontera de la realidad social y la ensoñación.

Sin embargo, tanto en uno como en otro texto los protagonistas se erigen desde su identidad convulsa y ambigua, la cual no entra en contradicción con el universo ficcional de la novela negra. La ambigüedad y carencia de escrúpulos es un rasgo heredado de los legendarios private eye del realismo noir norteamericano, de esa primitiva novela negra en la que se observa a detectives privados provocando auténticas guerras civiles -"El agente de la Continental" en Cosecha roja- o a extremistas juzgando y sentenciando a los criminales -Mike Hammer en Yo, el jurado.

Pepe Carvalho y Filiberto García se condenaron por sus acciones del pasado. Tanto uno como otro fueron héroes que emergieron de una historia impiadosa y cuyas acciones estuvieron saturadas de resultados arrasadores, de sueños de redención convertidos en horribles pesadillas que señalaron la fragilidad del propio héroe: el destino de una voluntad incapaz de sustraerse de la violencia y la irracionalidad (Forster 32).

Ambos construyeron su propia tragedia heroica, ya que al consumar su destino, sufrir la persecución, la cárcel y el exilio en defensa de sus ideales o pelear y matar en los campos de batalla por los principios de la Revolución, aceleraron su salida de la historia: se convirtieron en mitos.

No obstante, ni uno ni otro aceptaron ser objetos de pedestal, tal y como el propio García lo resume al negarse a pertenecer al panteón de los íconos revolucionarios: 
-Un hombre rudo, como los grandiosos Centauros del Norte que hicieron la Revolución...

¡Pinche señor del Valle! De a mucho discurso de fiestas patrias y toda la cosa. Ruda sería su madre, desgraciado [...] (Bernal 49).

El desmoronamiento del sentido se llevó consigo la salvación y la revolución y dejo solos a Carvalho y García ante su propia desesperación. Ambos son testigos del fin de la esperanza que comenzó a gestarse en los triunfos heroicos. Ante su condición de individuos marginados y contradictorios se erigen los dos como antihéroes y a través de su visión marginada ambos denuncian los vicios de sus sociedades (Mora Álvarez 2).

Estos dos antihéroes actúan de un modo diametralmente opuesto. Carvalho se erige como el agente doble idóneo que cumple a la perfección su misión semionarrativa. Genera la confianza suficiente en los Kennedy como para formar parte de ese íntimo circulo y así disparar sin ser sospechoso. García es el perfecto hombre de acción que evita una contrarrevolución que amenaza con crear una nueva guerra civil. No obstante, ninguno de estos antihéroes es recompensado.

La retribución final de Pepe Carvalho como agente de la CIA que formó parte del complot en contra de Kennedy no concluye con el correspondiente pago. El agente español es visto como una amenaza en contra de Wonderful y mister $\mathrm{H}$ y por eso debe ser eliminado:

-Yo quiero la parte de Pepe Carvalho.

-¿Por qué?

-No estaba previsto que yo le matara. Su muerte le cuesta a usted su parte.

-Aún no lo ha hecho.

-Es cuestión de minutos [...]

- ¡Morrison! ¡Mátele! ¡Inmediatamente! (Vázquez Montalbán 99, 112)

Sin embargo, Pepe Carvalho tiene un futuro en el que se desenvolverá a lo largo de los años visitando lugares conocidos en su pasado que continuará estando presente, aunque el reconvertido detective gallego tendrá que pagar un precio por sus acciones: nunca recuperará el objeto de su anhelo.

Para García el final es distinto. Ha completado su objetivo y eliminado cualquier amenaza al sistema, pero ha quedado totalmente vacío al perder la esperanza de que la Revolución lo recompensara por salvarla nuevamente, como un héroe emergido del desencanto: 
García seguía caminando. Las manos me están pesando, demasiado, como si llevara piedras en ellas. Liu la mató. Yo maté a Liu. Me están pesando las manos. Me duelen, como muchas muertes juntas. Tengo ganas de sentarme aquí en la banqueta... en una piedra del campo, como antes en la orilla del camino. Pero ya no hay caminos que andar con las manos que me pesan, que me duelen con tantas muertes que llevo dentro. ¡Pinches manos! [...] La pistola le dolía sobre el corazón. ¡Pinche velorio! ¡Pinche soledad! (Bernal 95, 96).

A diferencia de Pepe Carvalho, García ha propiciado su propia doble tragedia. Como héroe se condenó y quedo relegado, como antihéroe intentó ser nuevamente un héroe, pero una vez acabada la misión no había posibilidad de regresar a la condición de antihéroe.

\section{Bibliografía}

Bernal, Rafael. El complot mongol. México: Joaquín Mortíz, 1994.

Forster, Ricardo. La muerte del héroe. Buenos Aires: Ariel, 2011.

Greimas, Algirdas Julius. Maupassant. La sémiotique du texte: exercises practiques. París: Seuil, 1976.

Mora Álvarez, Luis. La representación del antihéroe en la literatura peninsular y latinoamericana. Ann Harbor, Michigan: UMI, 2007.

Moya Bedoya, Juan Diego. "Acerca de Yo maté a Kennedy de Manuel Vázquez Montalbán.” Revista de Artes y Letras 32.2 (2008): 25-32.

Múgica, Fernando. "Goliat humillado" La aventura de la Historia 178 (2013): 68-71.

Novo, Santiago. La vida en México en el periodo presidencial de Manuel Ávila Camacho México: Edits, 1965.

O'Donnell, Kevin. "Lost in the Supermarxist: The Appeal of Pepe Carvalho." Arizona Journal of Hispanic Cultural Studies 9 (2005): 137-147.

Prada Oropeza, Renato. Análisis e interpretación del discurso narrativo literario, Tomo 1. Zacateza: Universidad Autónoma de Zacatecas, 1993.

Vázquez Montalbán, Manuel. La soledad del manager. Barcelona: Planeta, 1977. . Asesinato en el Comité Central. Barcelona: Planeta, 1981. . Los pájaros de Bangkok. Barcelona: Planeta, 1983. . El balneario. Barcelona: Planeta, 1986. Yo maté a Kennedy. Impresiones, observaciones y memorias de un guardaespaldas. Barcelona: Planeta, 2012. . Tatuaje. Barcelona: Planeta, 2013. 